\title{
New Killer Toxins of Halophilic Hansenula anomala
}

\author{
Shogo Kagiyama, Tomio Aiba, Kiyoshi Kadowaki \\ and Koya Mogi \\ Research Laboratory, Higeta Shoyu Co., Ltd., Choshi-shi, Chiba 288, Japan \\ Received April 8, 1987
}

\begin{abstract}
Two strains of killer yeasts, both identified as Hansenula anomala, were isolated from shoyu moromi. Both killer yeasts showed killer activity toward $Z$ ygosaccharomyces rouxii EA under high salt concentration conditions. The killer toxins produced by these strains were purified by ultrafiltration and ion-exchange chromatography followed by gel filtration. The molecular weights of the toxins were about $300 \mathrm{kd}$ and both toxins were glycoproteins. The isoelectric point of the toxin, Kh-I, produced by one strain was $\mathrm{pH} 2.9$ and that of the toxin, $\mathrm{Kh}-\mathrm{II}$, produced by the other strain was $\mathrm{pH}$ 3.6. The amino acid composition of Kh-I was different from that of Kh-II. Kh-II was more thermolabile than Kh-I. The killer activities of both toxins were not observed in the absence of $\mathrm{NaCl}$ in the medium but increased with increasing $\mathrm{NaCl}$ concentration. The killer spectra of Kh-I and Kh-II were different from those of the killer toxins known as $K_{1}-K_{11}$. The killer activities of these strains were not abolished by cycloheximide treatment and by cultivation at $37^{\circ} \mathrm{C}$. No plasmid was detected in either killer yeast.
\end{abstract}

The killer character of Saccharomyces cerevisiae was first reported by Bevan and Makower. ${ }^{1}$ Thereafter a number of killer yeast strains were isolated from various natural habitats and classified according to their killing specificities. ${ }^{2)}$

The purification and properties of the killer toxins of $S$. cerevisiae, ${ }^{3 \sim 6)}$ Candida glabrata, ${ }^{7)}$ Pichia kluyveri, ${ }^{8)}$ Kluyveromyces lactis, ${ }^{9}{ }^{9}$ Hansenula mrakii ${ }^{10)}$ and Hansenula saturnus ${ }^{11)}$ have been reported. But the existence of a killer character in halophilic yeasts has not previously reported. There are many kinds of killer strains in a wide variety of yeasts. This suggests that there should be killer strains among halophilic yeasts. If halophilic killer yeasts are isolated, they will be useful for microbial control in shoyu making. We tried to isolate killer yeasts from shoyu moromi and successfully isolated two different killer yeast strains, and found that they produced killer toxins with unique characteristics, whose activities appeared in medium containing a high concentration of $\mathrm{NaCl}$, but not in its absence.

This paper describes the purification and various physicochemical properties of the killer toxins produced by these yeasts.

\section{MATERIALS AND METHODS}

Yeast strains. Zygosaccharomyces rouxii EA from the yeast collection of Higeta Shoyu Co., Ltd. was used as the test strain for the detection of killer activity. S. cerevisiae NCYC 235, S. cerevisiae NCYC 738, S. capensis NCYC 761, C. glabrata NCYC 388, $H$. anomala NCYC 434, $K$. fragilis NCYC 587, C. valida NCYC 327, $H$. anomala NCYC 435, H. mrakii NCYC 500, K. drosophilarum NCYC 575 and $C$. glabrata ATCC 15126 were used as standard killer strains with different killer sensitivities. ${ }^{2,12\rangle}$

Media. YEPD-1 medium (glucose $2 \%$, polypeptone $2 \%$, yeast extract $1 \%, 0.1 \mathrm{M}$ citrate phosphate buffer, $\mathrm{pH} 4.8$ ) and YEPD-2 medium (YEPD-1 medium containing $\mathrm{NaCl}$ $8 \%$ ) were used for cultivation of the killer yeasts. YEPDMB1 agar (YEPD-1 medium containing methylene blue $0.03 \%$ and agar $2 \%$ ) and YEPD-MB2 agar (YEPD-MB1 agar supplemented with $8 \% \mathrm{NaCl}$ ) were used for the isolation of killer yeasts. For the curing test on the killer activity, YM agar (glucose $1 \%$, polypepton $0.5 \%$, yeast extract $0.3 \%$, malt extract $0.3 \%$, agar $2 \%$ was used.

Detection of killer yeasts. The detection of killer yeasts was performed by the cross-streak test, ${ }^{13)}$ as fol- 
lows. Z. rouxii EA was inoculated on YEPD-MBI and YEPD-MB2 agar plates and then the strain to be tested for killing activity was cross-streaked on them, followed by incubation at $23^{\circ} \mathrm{C}$ for 4 days. If the strain had killer activity, then the cells of $Z$, rouxii EA became blue due to methylene blue staining.

Taxonomic identification of yeasts. Taxonomic identification of the killer strains was carried out according to the methods of Kregar-van $\mathrm{Rij}^{14}{ }^{14}$

Determination of killer activity. Killer activity was determined by the cup method. Killer yeast cultures were filtered through $0.2 \mu \mathrm{m}$ nitrocellulose membrane filters. $0.1 \mathrm{ml}$ portions of the filtrates were pipetted into cups ( $6 \mathrm{~mm}$ inside diameter) on YEPD-MB2 agar plates, each inoculated with $10^{5}$ cells of the test strain. The plates were incubated at $23^{\circ} \mathrm{C}$ for 4 days. The diameter of the inhibitory zone around each cup was measured and the area of the inhibitory zone was calculated. One unit (U) is the amount of killer toxin that inhibits one square $\mathrm{cm}$ of the test strain.

Biochemical methods. Carbohydrate was analyzed by gas chromatography (Yanako G-180) of trimethylsilyl derivatives, ${ }^{15)}$ after hydrolysis of the toxin sample in $2 \mathrm{~N}$ $\mathrm{HCl}$ at $100^{\circ} \mathrm{C}$, on a column packed with Silicone GS-101 (Gasukurokogyo Inc.) $(3 \mathrm{~mm} \times 2 \mathrm{~m}$ glass column). The amino acid composition was determined with an amino acid analyzer (Shimadzu Liquid Chromatograph LC6A) after hydrolysis of the toxin sample in $6 \mathrm{~N} \mathrm{HCl}$ at $110^{\circ} \mathrm{C}$ for $22 \mathrm{hr}$. The amounts of protein were determined by the method of Lowry et al. ${ }^{16)}$ with bovine serum albumin as a standard, and those of carbohydrate by the phenolsulfuric acid method. ${ }^{17)}$ To examine the effect of proteolytic enzymes on the killer activity, pepsin, papain and chymotrypsin $\mathrm{A}_{4}$ (Boehringer Mannheim $\mathrm{GmbH}$, W. Germany), and the crude enzyme of Aspergillus sojae were used.

\section{RESULTS}

\section{Isolation of killer yeasts}

Six hundred and twenty-three osmophilic yeast strain isolated at random from shoyu moromi in our plants were tested as to killer activity using cells of $Z$. rouxii EA as the standard sensitive strain. Two strains showed activity on YEPD-MB2 agar but not on YEPDMB1 agar.

\section{Taxonomic characterization of killer yeasts}

The 2 killer strains formed pseudomycelia and ascospores (hat-shaped). But true mycelia and ballispores were not formed. Both strains assimilated nitrate but did not produce acetic acid. So both strains were classified as Hansenula. Both strains fermented sucrose and were able to grow in vitamin-free medium. Both strains assimilated maltose, erythritol and soluble starch but not L-rhamnose. From the above results both killer strains were identified as Hansenula anomala.

\section{Purification of killer toxins}

The killer strains were grown at $23^{\circ} \mathrm{C}$ for 4 days in YEPD-2 medium. Thereafter, all the steps were performed at $5^{\circ} \mathrm{C}$. The culture broths, about 101 in volume, were filtrated with Hyflo Supercells. The filtrates were concentrated to $50 \mathrm{ml}$ with hollow fiber H1P-10 (Amicon). For desalting, the concentrated solutions were applied to a column of Sephadex G-25 $(5 \times 90 \mathrm{~cm})$ equilibrated with $50 \mathrm{~mm}$ citrate phosphate buffer $(\mathrm{pH} 4.8)$ and eluted with the same buffer. The active fractions, totaling $600 \mathrm{ml}$, were applied to a column of SPSephadex C-25 $(5 \times 50 \mathrm{~cm})$ equilibrated with $10 \mathrm{~mm}$ citrate phosphate buffer ( $\mathrm{pH} 4.8)$. After washing the column with buffer, elution was performed with a $1000 \mathrm{ml}$ linear gradient of

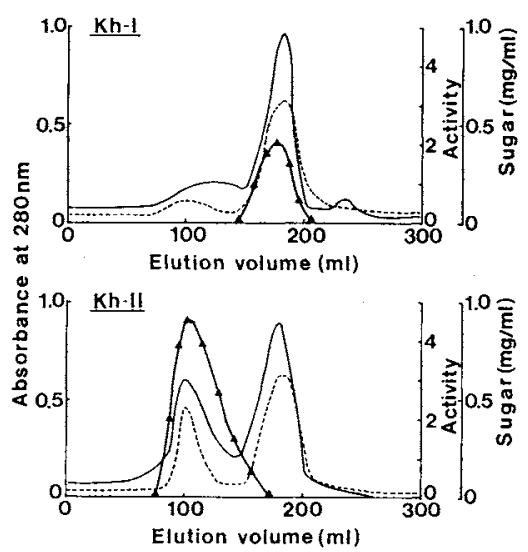

FIG. 1. Gel Filtration of the Kh-I and Kh-II Toxins on Toyopearl HW60.

The Kh-I and Kh-II toxins were produced, respectively, by two independent isolates of $H$. anomala. $\mathbf{\Delta}-\mathbf{\Delta}$, killer activity; --.--, absorbance at $280 \mathrm{~nm}$; concentration. Column size, $2.6 \times 90 \mathrm{~cm}$; flow rate, $60 \mathrm{ml} / \mathrm{hr}$. 
$0 \sim 1 \mathrm{~m} \mathrm{NaCl}$. The active fractions, $450 \mathrm{ml}$, were collected and concentrated by ultrafiltration (PM 10, Amicon) and then the concentrated sample (ca. $10 \mathrm{ml})$ was chromatographed on Toyopearl HW60 $(2.6 \times 90 \mathrm{~cm})$ equilibrated with $100 \mathrm{~mm}$ citrate phosphate buffer ( $\mathrm{pH} 4.8$ ). Typical elution profiles for the killer toxin, Kh-I, produced by one of the isolates and that, $\mathrm{Kh}-\mathrm{II}$, produced by the other yeast strain isolated are shown in Fig. 1. It was evident from the elution profiles that the killer activities are identical with those of proteins and carbohydrates. These facts strongly suggest that the Kh-I and Kh-II toxins are glycoproteins. The active fractions were then collected, dialyzed and lyophilized.

Polyacrylamide gel electrophoresis of the active fractions was carried out with a $7.5 \%$ polyacrylamide slab gel according to the method of Davis. ${ }^{18)}$ After electrophoresis, the protein bands were visualized by staining with Coomassie Brilliant Blue G 250. It was confirmed that each lyophilized preparation, Kh-I and $\mathrm{Kh}-\mathrm{II}$, gave a single protein band on gel electrophoresis (data not shown).

\section{Characteristics of the killer toxins}

Molecular weight. The molecular weights of the $\mathrm{Kh}-\mathrm{I}$ and $\mathrm{Kh}$-II toxins were estimated from the elution profiles on Sepharose CL6B gel chromatography (Fig. 2). The molecular

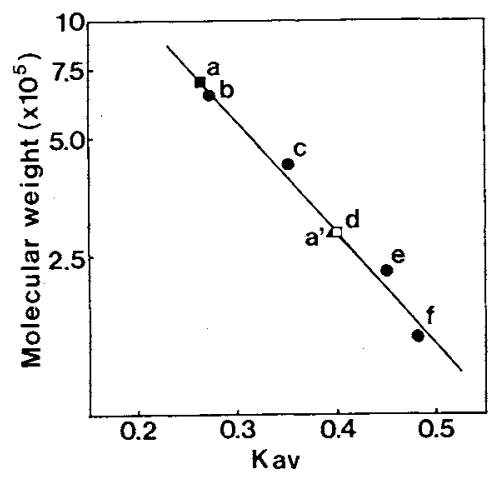

Fig. 2. Determination of the Molecular Weights of the Kh-I and Kh-II Toxins by Gel Filtration on Sepharose CL6B

a, Kh-II; b, thyroglobulin; c, ferritin; d, Kh-I; e, catalase; f, aldolase; $\mathrm{a}^{\prime}, \mathrm{Kh}$-II after hydro-carboxamide-methylation. weight of $\mathrm{Kh}$-I was estimated to be about $300 \mathrm{kd}$ and that of $\mathrm{Kh}-\mathrm{II}$ to be about $700 \mathrm{kd}$. These molecular weights are very large for secretion products of yeasts. Therefore, the toxins might have undergone subunit aggregation. To examine this, hydro-carboxamidmethylation ${ }^{19)}$ of the Kh-I and Kh-II preparations was performed. On hydrocarboxamidmethylation, the molecular weight of Kh-I did not change, but that of $\mathrm{Kh}$-II decreased from $700 \mathrm{kd}$ to $300 \mathrm{kd}$. This suggests that aggregation through disulfide bond formation of the Kh-II toxin occurred during the purification process and that the molecular weight of the intact $\mathrm{Kh}-\mathrm{II}$ toxin is about $300 \mathrm{kd}$.

Isoelectric point. The isoelectric point was determined by isoelectric focusing. ${ }^{20)}$ It was conducted at $5^{\circ} \mathrm{C}$ for $72 \mathrm{hr}$ at $700 \mathrm{~V}$ in a glycerol gradient solution with carrier ampholytes (LKB, pH range, 2.5 4.0). The isoelectric point of the $\mathrm{Kh}-\mathrm{I}$ toxin was estimated to be 2.9 and that of Kh-II to be 3.6.

Contents of protein and carbohydrate. The Kh-I toxin was composed of $53 \%$ protein and $47 \%$ carbohydrate, and Kh-II of $49 \%$ protein and $51 \%$ carbohydrate. These results indicate that both toxins are glycoproteins.

Carbohydrate composition. Figure 3 shows the results of GLC analysis of the products of TMS ethers obtained from acid hydrolysates of the Kh-I and Kh-II toxins. In Fig. 3, peaks $1 \mathrm{a}, 3 \mathrm{a}, 1 \mathrm{~b}$ and $3 \mathrm{~b}$ were identified as Dmannose, and peaks $2 a, 5 a, 2 b$ and $5 b$ as D-

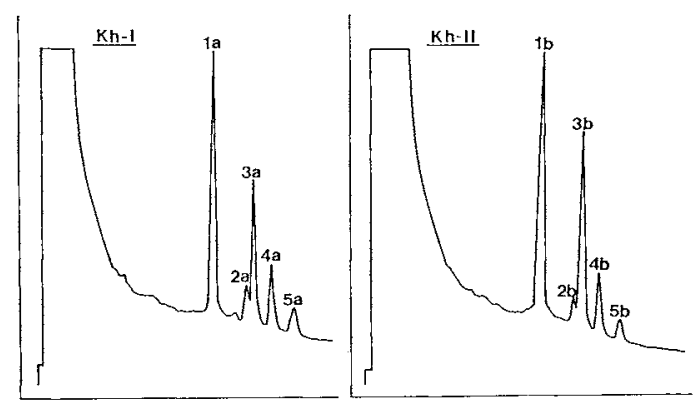

FIG. 3. Gas Chromatography of TMS Sugars Obtained from Acid Hydrolysates of Kh-I and Kh-II Toxins.

la, 3a, 1b, 3b, mannose; 2a, 5a, 2b, 5b, glucose; 4a, 4b, mannitol (internal standard). 
TABle I. Amino ACID Analysis of the Kh-I AND Kh-II TOXINS

\begin{tabular}{lrr}
\hline & No. of residues per molecule of \\
\cline { 2 - 3 } Amino acid & Kh-I $^{a}$ & Kh-II \\
\hline Aspartic acid & 128 & 152 \\
Threonine & 92 & 91 \\
Serine & 90 & 128 \\
Glutamic acid & 271 & 106 \\
Proline & 108 & 53 \\
Glycine & 88 & 111 \\
Alanine & 58 & 82 \\
Cystine & 5 & 6 \\
Valine & 70 & 62 \\
Methionine & 18 & 5 \\
Isoleucine & 67 & 38 \\
Leucine & 54 & 130 \\
Tyrosine & 14 & 33 \\
Phenylalanine & 30 & 77 \\
Histidine & 46 & 23 \\
Lysine & 85 & 50 \\
Arginine & 14 & 24 \\
\hline
\end{tabular}

a Mass of killer protein per one molecule was estimated to be $159 \mathrm{kd}$.

$b$ Mass of killer protein per one molecule was estimated to be $149 \mathrm{kd}$.

glucose. These data indicate that the carbohydrate of the $\mathrm{Kh}-\mathrm{I}$ toxin consists of $79 \% \mathrm{D}-$ mannose and $21 \% \mathrm{D}$-glucose, the proportions being $86 \%$ D-mannose and $14 \% \mathrm{D}$-glucose for the $\mathrm{Kh}$-II toxins.

Amino acid composition. The results of amino acid analysis of the Kh-I and Kh-II toxins are presented in Table I. They have different compositions. In particular, the contents of glutamic acid, proline, methionine, isoleucine and lysine of the Kh-I toxin were higher than those of Kh-II.

Effect of the $\mathrm{NaCl}$ concentration of the killer activity. Figure 4 shows the killer activities of the lyophilized preparation of the $\mathrm{Kh}-\mathrm{I}$ and $\mathrm{Kh}-\mathrm{II}$ toxins with the cup method when the $\mathrm{NaCl}$ concentration of YEPD-MBl agar was changed in the range of $0 \sim 16 \%$. In the absence of $\mathrm{NaCl}$ the killer activities of both toxins were not observed but increased in accordance with $\mathrm{NaCl}$ concentration.

pH stability of the killer activity. Solutions of the Kh-I and $\mathrm{Kh}-\mathrm{II}$ toxins were adjusted to

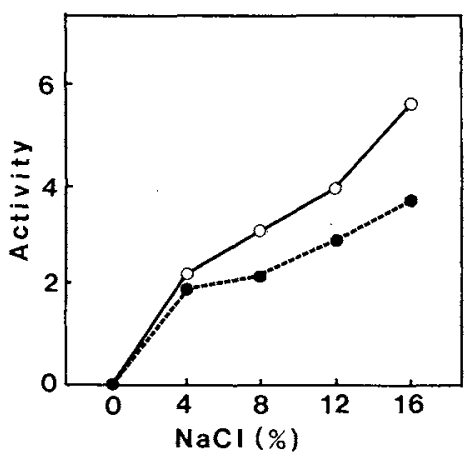

FIG. 4. Effect of the $\mathrm{NaCl}$ Concentration on the Killer Activities of the Kh-I and Kh-II Toxins.

The killer activities of the lyophilized toxin preparation were determined by the cup method using $Z$. rouxii EA as the sensitive test strain. $\mathrm{O}$, the $\mathrm{Kh}-\mathrm{I}$ toxin preparation; the Kh-II toxin preparation.

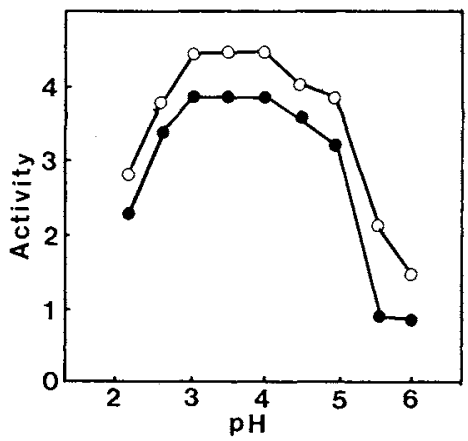

FIG. 5. pH Stabilities of the Killer Activities of the Kh-I and Kh-II Toxins.

$O$, the Kh-I toxin preparation; - , the Kh-II toxin preparation.

various $\mathrm{pHs}$ from 2.0 to 6.0 with $1 \mathrm{M}$ citrate phosphate buffer and then kept at $5^{\circ} \mathrm{C}$ for $18 \mathrm{hr}$. After the incubation, each solution was assayed for killer activity. Figure 5 shows that both toxin preparations were stable from $\mathrm{pH} 2.5$ to 5.0 under the above conditions.

Thermal stability of the killer activity.. Solutions of the Kh-I and Kh-II toxins were incubated in the range of $15 \sim 45^{\circ} \mathrm{C}$. After $15 \mathrm{~min}$ to $4.5 \mathrm{hr}$, the solutions were assayed for activity. The killer activities of the Kh-I and $\mathrm{Kh}$ II preparations decreased with increasing of temperature (Fig. 6). After $4.5 \mathrm{hr}$ incubation at $45^{\circ} \mathrm{C}$, the $\mathrm{Kh}-\mathrm{I}$ sample showed $40 \%$ of the initial activity, while incubation of the Kh-II 
preparation at $35^{\circ} \mathrm{C}$ for $30 \mathrm{~min}$ led to complete loss of the activity. These results indicated that the Kh-I toxin is more stable at high temperature than Kh-II.

Effects of proteolytic enzymes. Solutions of $5 \mathrm{mg} / \mathrm{ml}$ pepsin, $2 \mathrm{mg} / \mathrm{ml}$ papain, $2 \mathrm{mg} / \mathrm{ml}$ chymotrypsin $\mathrm{A}_{4}$ and $6.4 \mathrm{mg} / \mathrm{ml}$ crude enzyme of $A$. sojae were used. For the preparation of the crude enzyme of $A$. sojae, a bran medium $(50 \mathrm{~g}$ of wheat bran mixed with $40 \mathrm{ml}$ of tap water and then autoclaved for $30 \mathrm{~min}$ ) was used. The bran medium inoculated

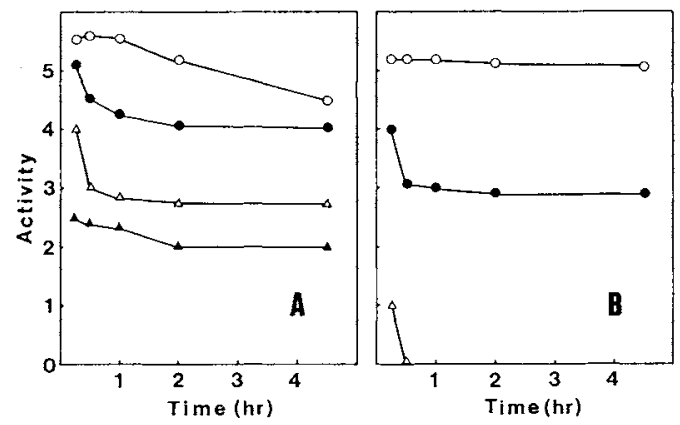

FIG. 6. Thermostabilities of the Killer Activities of the Kh-I and Kh-II Toxins.

$\mathrm{A}$, the $\mathrm{Kh}-\mathrm{I}$ toxin preparation; $\mathrm{B}$, the $\mathrm{Kh}-\mathrm{II}$ toxin preparation. $\bigcirc, 15^{\circ} \mathrm{C} ; 25^{\circ} \mathrm{C} ; \triangle, 35^{\circ} \mathrm{C} ; \Delta, 45^{\circ} \mathrm{C}$. with $A$. sojae was incubated at $30^{\circ} \mathrm{C}$ for $48 \mathrm{hr}$ and then the medium was mixed with $50 \mathrm{ml}$ of $0.1 \mathrm{M}$ citrate-phosphate buffer ( $\mathrm{pH} 4.8$ ), followed by filtration. The filtrate was lyophilized and used as the crude enzyme of $A$. sojae.

The lyopilized toxin preparations were mixed with $0.5 \mathrm{ml}$ of enzyme solutions and then incubated at $15^{\circ} \mathrm{C}$ for $38 \mathrm{hr}$. After incubation, the killer activities were assayed. The effects of denatured enzymes, heated at $100^{\circ} \mathrm{C}$ for 15 min, were also examined.

The Kh-I toxin was inactivated by papain but not by pepsin or chymotrypsin $\mathrm{A}_{4}$. The $\mathrm{Kh}$-II toxin was not inactivated by pepsin, papain or chymotrypsin $\mathrm{A}_{4}$. However, both toxin preparations lost about $60 \%$ of their killer activities on treatment with the crude enzyme of $A$. sojae.

Anti-yeast spectra of the Kh-I and Kh-II toxins. Table II shows anti-yeast spectra of the $\mathrm{Kh}-\mathrm{I}$ and $\mathrm{Kh}-\mathrm{II}$ toxins determined by the cross-streek method. The Kh-I toxin killed the $\mathrm{K}_{6}, \mathrm{~K}_{10}$ and $\mathrm{K}_{11}$ type killer yeasts, depending on the $\mathrm{NaCl}$ concentration in the medi$\mathrm{um}$, and the $\mathrm{Kh}$-II toxin killed the $\mathrm{K}_{2}, \mathrm{~K}_{3}$, $\mathrm{K}_{7}, \mathrm{~K}_{10}$ and $\mathrm{K}_{11}$ type killer yeasts. It is evident that the killer spectra of both the $\mathrm{Kh}-\mathrm{I}$

TABLE II. Anti-yeast Spectra of the Kh-I AND Kh-II Toxins

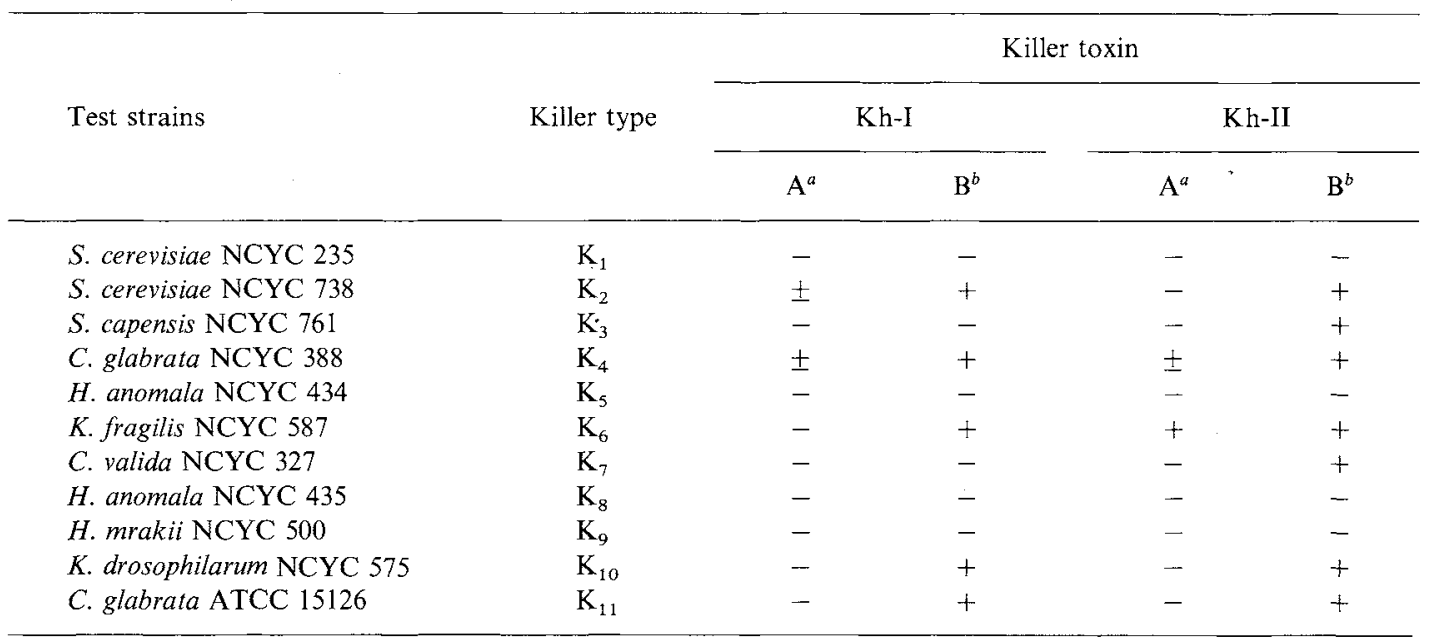

a Tested on YEPD-MBl agar $(\mathrm{NaCl} 0 \%)$.

$b$ Tested on YEPD-MB3 agar $(\mathrm{NaCl} 4 \%)$.

+ , killing; - , no killing; \pm , weak killing. 
and $\mathrm{Kh}-\mathrm{II}$ toxins are different from those of the $\mathrm{K}_{1} \sim \mathrm{K}_{11}$ types reported by Young and Yagiu. $^{2)}$

\section{Curing test}

Cells of the killer yeasts were diluted with a sterile $0.9 \% \mathrm{NaCl}$ solution and then $0.1 \mathrm{ml}$ of each solution (containing about 100 cells) was spread on a YM agar plate. To examine the curing of the killer characteristics of the isolated $H$. anomala strains with cycloheximide, media containing $0.1 \mathrm{ppm}$ of cycloheximide were prepared by the aseptic addition of the filter-sterilized antibiotic to autoclaved $\mathrm{YM}$ agar, and the plates were incubated at $30^{\circ} \mathrm{C}$. To examine the cultivation temperature for the curing of the killer characteristics, plates without cycloheximide were incubated at $37^{\circ} \mathrm{C}$. After $48 \mathrm{hr}$ incubation, the plates were replicated onto YEPD-MB2 agar, which had been inoculated with the sensitive cells $2 \mathrm{hr}$ before, followed by incubation at $23^{\circ} \mathrm{C}$ for 4 days.

The killer activities of the 2 killer yeast strains were not cured by cycloheximide treatment or incubation at $37^{\circ} \mathrm{C}$.

\section{Detection of plasmids}

Detection of plasmids was attempted by the procedure of Gunge et al. ${ }^{21)}$ However, no plasmid was detected in either yeast.

\section{DISCUSSION}

It has been reported that the killer toxins in $S$. cerevisiae, C. glabrata, $P$. kluyveri and $K$. lactis are glycoproteins. But the molecular weights of the $\mathrm{Kh}-\mathrm{I}$ and $\mathrm{Kh}-\mathrm{II}$ toxins are three times greater than that of the toxin of $K$. lactis IFO 1267, which has the largest molecular weight so far reported. The proportions of carbohydrate in the Kh-I and $\mathrm{Kh}$ II toxins are five as high as that in the $S$. cerevisiae toxin, besides which the isoelectric points of the Kh-I and Kh-II toxins were lower than those of most of the other known toxins. The $\mathrm{pI}$ of the Kh-I toxins was the lowest for the toxins so far isolated. Furthermore, the killer spectra of both the Kh-I and $\mathrm{Kh}$-II toxins are quite different from those of the $\mathrm{K}_{1} \sim \mathrm{K}_{11}$ toxins. Therefore, the $\mathrm{Kh}-\mathrm{I}$ and $\mathrm{Kh}$-II toxins are new species of killer toxins. Moreover, judging from its thermal stability, amino acid composition and killer spectra, the Kh-I toxin is distinctly different from the Kh-II toxin. Invertase ${ }^{22)}$ and acid phosphatase $^{23)}$ of $S$. cerevisiae are well known as secreted glycoproteins, whose molecular weights and sugar contents are similar to the Kh-I and Kh-II toxins. But these enzymes exist in the cell wall and are never secreted into the medium. There has been no report of such a large glycoprotein being secreted into the medium and it is very interesting that two killer strains secreting such large substances existed in shoyu moromi.

That the Kh-I and Kh-II toxins killed $Z$. rouxii EA depending on the $\mathrm{NaCl}$ concentration showed that the $\mathrm{Kh}-\mathrm{I}$ and $\mathrm{Kh}-\mathrm{II}$ toxins are halophilic factors. The effect of $\mathrm{NaCl}$ on the killer activity of the killer toxin of $S$. cerevisiae was also investigated by Palfree et $a l^{3)}$ These authors reported, however, that the killer activity decreased with increasing $\mathrm{NaCl}$ concentration.

Killer plasmids were detected in the $\mathrm{K}_{1} \sim \mathrm{K}_{3}$ types of killer yeasts. However, the killer activities of the present, two killer yeast strains, $H$. anomala strains $\mathrm{Kh}-\mathrm{I}$ and $\mathrm{Kh}-\mathrm{II}$, were not cured by cycloheximide treatment or incubation at $37^{\circ} \mathrm{C}$, and no plasmid was detected in either yeast. These results suggest that the genetic basis for the toxin production in these strains is a chromosomal gene and not a cytoplasmic factor.

In shoyu moromi, the concentration of $\mathrm{NaCl}$ is very high and activities of proteases derived from Aspergillus sojae are also high. In order to exhibit killer activity under such conditions, a killer toxin must be halophilic and tolerant to proteases. The isolated yeast strains, $H$. anomala strains $\mathrm{Kh}-\mathrm{I}$ and Kh-II, are able to grow at such a high concentration of $\mathrm{NaCl}$ as that in shoyu moromi. In addition, the toxins of these killer yeasts are halophilic factors, and both toxin preparations exhibit 
about $40 \%$ of the initial killer activity after treatement with the crude enzyme of $A$. sojae. These facts indicate that these killer yeasts can grow and express their activities in shoyu moromi. So, in shoyu brewing, we can use these killer yeasts to control lactic acid and alcoholic fermentation in moromi for good quality of the product.

Acknowledgment. We wish to thank Miss Keiko Kase and Miss Kayoko Miyauchi of our laboratory for their technical assistance.

\section{REFERENCES}

1) E. A. Bevan and M. Makower, Proceedings 11th International Congress of Genetics, Vol. 1, 1963, p. 203.

2) T. W. Young and M. Yagiu, Antonie van Leeuwenhoek, 44, 59 (1978).

3) R. G. E. Palfree and H. Bussey, Eur. J. Biochem., 93, 487 (1979).

4) P. Pfeiffer and F. Radler, J. Gen. Microbiol., 128, 2699 (1982).

5) P. Pfeiffer and F. Radler, Arch. Microbiol., 137, 357 (1984).

6) K. A. Bostian, Q. Elliot, H. Bussey, V. Burn, A. Smith and D. J. Tipper, Cell, 36, 741 (1984).

7) H. Bussey and N. Skipper, J. Bacteriol, 124, 476
(1975).

8) E. J. Middelbeek, J. M. H. Hermans and C. Stumm, Antonie van Leeuwenhoek, 45, 437 (1979).

9) Y. Sugisaki, N. Gunge, K. Sakaguchi, M. Yamasaki and G. Tamura, Seikagaku, 54, 648 (1982).

10) S. Ashida, T. Shimazaki, K. Kitano and S. Hara, Agric. Biol. Chem., 47, 2953 (1983).

11) Y. Ohta, Y. Tsukada and T. Sugimori, Agric. Biol. Chem., 48, 903 (1984).

12) R. B. Wickner, Plasmid, 2, 303 (1979).

13) G. R. Fink and C. A. Styles, Proc. Natl. Acad. Sci. U.S.A., 69, 2846 (1972).

14) N. J. W. Kreger-van Rij, "The Yeasts, A Taxonomic Study," B. V. Elsevier Science Publishers, Amsterdam, 1984.

15) D. A. Craven and C. W. Gehrke, J. Chromatogr., 37, 414 (1968).

16) R. R. Lowry and I. J. Tinsley, Lipids, 9, 491 (1974).

17) M. Dubois, K. A. Gilles, J. K. Hamilton, P. A. Rebers and F. Smith, Anal. Chem., 28, 350 (1956).

18) B. J. Davis, Ann. N. Y. Acad. Sci., 121, 404 (1964).

19) C. H. W. Hirs, "Methods of Enzymology," Vol. 11, ed. by C. H. W. Hirs, Academic Press, New York, 1967, p.199.

20) E. Doi and C. Ohtsuru, Agric. Biol. Chem., 38, 1747 (1974).

21) N. Gunge, A. Tamaru, F. Ozawa and K. Sakaguchi, J. Bacteriol., 145, 382 (1981).

22) S. Gascon, N. P. Neuman and J. O. Lampen, J. Biol. Chem., 243, I573 (1968).

23) P. Boer, Ph.D. Thesis, 1, Utrecht (The Netherlands). 